\title{
Knowledge, Attitude and Practices of Mothers Regarding 'Oral Rehydration Therapy' in Jammu Slums
}

\author{
Ramesh Chander, M.D., ${ }^{1}$ Puja Vimesh, M.D., ${ }^{2}$ Shyam Singh, M.Ch. ${ }^{3}$ \\ 'Department of Family \& Community Medicine, Adesh Institute of Medical Sciences and Research, Bathinda, Punjab, ${ }^{2}$ Department of \\ Cardiothoracic Anaesthesia, Govt. Medical College, Jammu ${ }^{3}$ Departrment of Cardiovascular and Thoracic Surgery, Sher-i-Kashmir \\ Institute of Medical Sciences, Srinagar
}

\section{A B S T R A C T}

BACKGROUND: Little information is available among mothers living in Jammu slums regarding oral rehydration therapy(ORT).

OBJECTIVE: To study the knowledge, attitude and practices of mothers regarding oral rehydration therapy during diarrhoeal episode in their children?

STUDY DESIGN \& SETTING : A cross-sectional study, conducted in slums of Jammu city.

METHODS: A total of 750 mothers of children below 6 years of age suffering from diarrhoea were recruited for the study. The sample size was selected out of the total 3000 mothers of children suffering from diarrhoea by systematic random sampling technique. Mothers were contacted by house to house visits and in Anganwari centers.

RESULTS: Most of the mothers got first information about oral rehydration solution(ORS) from health personals (68.8\%) and $17.9 \%$ from mass-media. Majority considered it to be a home- made remedy of diarrhoea (40.5\%). They were knowing some forms of home-available fluids. The first line of action of mothers at the onset of diarrhoea was to consult health personnels (58\%). While $26.9 \%$ used ORS and the rest wanted it in combination with medicines. Only $12.54 \%$ and $22.33 \%$ mothers could prepare Sugar Salt Solution and ORS correctly, respectively. JMS 2012;15(2):1 11 - 14

Key words: Diarrhoea, dehydration, oral rehydration therapy, oral rehydration solution, sugar salt solution.

Oral rehydration therapy is a simple treatment for dehydration associated with diarrhoea. It consists of salts and sugar in water and is taken orally. It is used all over the world and saves millions of lives, especially infants. ${ }^{1}$ According to current WHO/UNICEF guidelines. ${ }^{2}$ ORS should begin at home at the first sign of diarrhoea to prevent dehydration. Feeding should be continued at all times during the episode of diarrhoea. ${ }^{3}$ The home-available fluids(HAF) and sugar salt solution (SSS) should contain proper proportions of sugar

\section{Correspondence:}

Dr. Ramesh Chander

103-A(Private), Gandhinagar, Jammu

E-mail: rameshvimesh@yahoo.com and salts. Salts compensate for hyponateremia and hypokalemia and sugar increases salt absorption through SGLTI transporter. ${ }^{4}$

$\mathrm{WHO} / \mathrm{UNICEF}$ ORS is available in all regions in premeasured sachets and is ready to be mixed in 1 liter of water. ${ }^{5}$ In 1996 UNICEF distributed 500 million such sachets in 60 developing countries. ${ }^{6}$ HAF's can be used as first remedial measures. SSS can be prepared by adding one level teaspoonfull of common salt, 8 teaspoonful of sugar, and 4 ounces of orange juice(optional) in 1 liter of potable water.

In 2003, WHO and UNICEF gave guidelines for Low Osmolarity ORS. ${ }^{8}$ which is available for commercial use and was updated in $2006 .{ }^{9}$ It's total Osmolarity is $245 \mathrm{mmol} / \mathrm{L} .{ }^{10}$ 
The benefits of reduced osmolarity ORS are: reducing stool volume by $25 \%$, reducing vomiting by nearly $30 \%$ and reducing need for IV fluid therapy by $33 \%{ }^{11}$

There is additional recommendation for zinc supplementation $^{12}$ for the management of diarrhoea. It reduces severity and duration of diarrhea, and is strongly recommended as supplement with ORS in dehydrated children.

\section{Methods}

The study was conducted among the mothers of children suffering from acute diarrhoeal attacks in the Jammu urban slums. A total of 750 mothers formed the sample size, which was selected by systematic random sampling technique out of the total 3000 mothers of children suffering from diarrhoea. Mothers were contacted by house to house visits and in anganwari centers. Study period was from May 2009 to September 2010.

A pre-tested, semi-structured, oral questionnaire comprising of $14 \mathrm{MCQs}$ were administered to mothers to ascertain their knowledge, attitude and practices regarding ORT. The first question to 750 mothers was: Have you ever heard of Oral rehydration solution? Only 558 mothers $(74.4 \%)$ were aware of ORS and they were our target population for finding out the results of our objectives, while the other 192, who had neither heard nor were aware of ORS (25.6\%) were not put to any further questioning and deleted from the study. Analysis of data was conducted using SPSS. The questionnaire introduced was, recommended by NICD.

\section{Results}

Majority of mothers received first information about ORS from health personnels (68.81\%) and $17.92 \%$ from mass-media(Table 1). Majority considered it to be a remedy for diarrhea (40.50\%). Approximately one fifth mothers $(17.20 \%)$ knew that these ORS packets which were available

TABLE I . Information to mothers regarding ORS

\begin{tabular}{llcc} 
S.No. & Source & Number of mother & $\%$ age \\
1. & Health Personnel & 384 & 68.81 \\
2. & Peer Group, Relatives, Neighbours & 74 & 13.26 \\
3. & TV, Radio, Print Media & 100 & 17.92 \\
\hline & Total & 558 & 100.00 \\
\hline
\end{tabular}

from chemist/health care workers were useful for diarrhea. However, a small number (11.82\%) did not have a clear idea about ORS, even though they had heard of it previously. Mothers' knowledge about HAF was limited to rice-ORS $23.29 \%$, Lemon-water $19.7 \%$, pulses water/tea $18.63 \%$, yogurt- water $9.86 \%$. However $8.9 \%$ mothers looked amuck.
During diarrhoea attack, majority of mothers (58\%) opined to consult a health personnel, one fourth $(22.2 \%)$ wanted to start ORS and only small fraction (9.1\%) believed in 'wait and watch policy' for self recovery (Table 2).

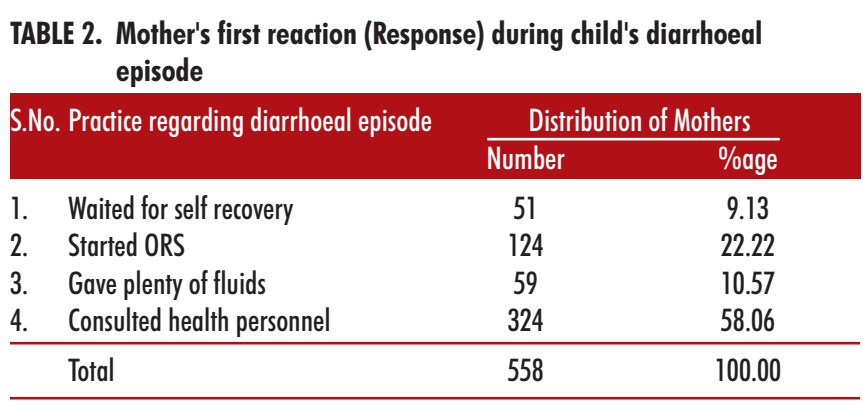

Regarding reasons of giving ORS to their children during diarrhoeal episode. 59 percent mothers were using it because it was cheap, easily available and prevented dehydration, while $41 \%$ mothers could not give any reason (Table 3 ). In this study, only 26.88 percent mothers expressed their satisfaction on being prescribed only ORS, while 73.12 had faith in medicines and ORS in combination(Table 4).

\section{TABLE 3. Reasons for giving ORS by mothers}

\begin{tabular}{lcc} 
S.No. Reasons & Number of mothers & \%age \\
$\begin{array}{l}\text { 1. } \\
\begin{array}{l}\text { Cheap, easy availability } \\
\text { prevents dehydration }\end{array}\end{array}$ & 329 & 59.00 \\
2. Not known & 229 & 41.00 \\
\hline Total & 558 & 100.00 \\
\hline
\end{tabular}

Regarding methods of preparation of SSS and ORS, only $12.54 \%$ and $22.93 \%$ mothers could prepare them correctly, respectively (Table 5,6). Only $24.1 \%$ mothers new that freshly prepared ORS was fit for consumption within 24 hours only (Figure 1). Feeds were withheld by 155 (27.7\%) mothers during diarrhoeal episode, while 403 (72.3\%) continued feeding (Figure 2).

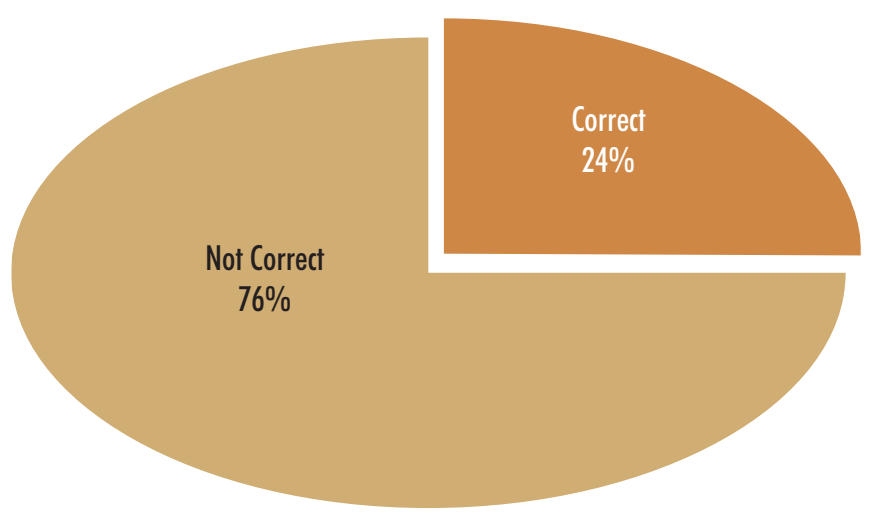

FIGURE 1. Knowledge of using of ORS after preparation 


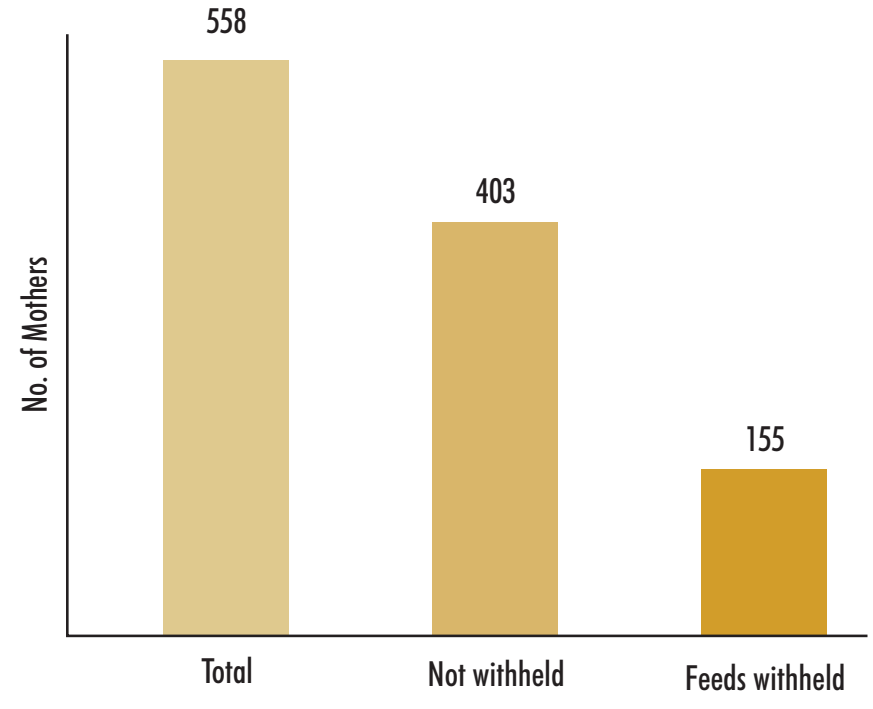

FIGURE 2. Mothers attitude of feeding of children during diarrhoea a study conducted by chaturvedi et $a l^{14}$, the response was $69.5 \%$ from health personnels, $15.9 \%$ TV/radio, $4.9 \%$ peer group and $1.2 \%$ print media.

Mothers were knowing some forms of HAFs. The study of Victoria CG et al $^{15}$, showed that $95 \%$ of the mothers had knowledge of at least one of the rehydration solution. Majority of mothers (58\%) opined to consult a health personnel, $22.2 \%$ wanted to start ORS at the first signal of diarrhea and $9.1 \%$ believed in waiting for self recovery (Table 2). In a study conducted by Sood AK et $a l^{16}$ the practice of mothers was to consult health personnel (57.66\%); 30.5\% wanted to start HAF. So, our study agrees with the author. Banakappa DG et al ${ }^{17}$ in their study observed that only $25 \%$ mothers were in favour of starting ORS.

Three hundred twenty nine (59\%) mothers were using ORS, because it was cheap, easily available and prevented dehydration, while $41 \%$ mothers could not give any reason

TABLE 4. Mothers attitude over ORS prescription

\begin{tabular}{|c|c|c|c|c|c|}
\hline \multirow[t]{2}{*}{ S.No. Item Prescribed } & \multicolumn{5}{|c|}{ Number of mothers } \\
\hline & Satisfied & \%age & Not satisfied & \%age & Total \\
\hline 1. ORS alone & 150 & 26.88 & 408 & 73.12 & $558(100 \%)$ \\
\hline 2. Ors and Medicines & 408 & 73.12 & 150 & 26.88 & $558(100 \%)$ \\
\hline
\end{tabular}

TABLE 5. Mothers knowledge of sugar salt solution preparation

\begin{tabular}{|c|c|c|}
\hline $\begin{array}{l}\text { S.No. Mothers knowledge about } \\
\text { preparation of SSS }\end{array}$ & Number of Mothers & \%age \\
\hline Had correct knowledge & 70 & 12.54 \\
\hline Did not have correct knowledge & 124 & 22.33 \\
\hline Not known & 364 & 65.23 \\
\hline Total & 558 & 100.00 \\
\hline
\end{tabular}

TABLE 6. Mother's knowledge of ORS preparation

\begin{tabular}{|c|c|c|}
\hline S.No. ORS preparation knowledge & Number & \%age \\
\hline 1. Correct & 128 & 22.93 \\
\hline Not correct & 174 & 31.17 \\
\hline 3. Not known & 256 & 45.9 \\
\hline Total & 558 & 100.00 \\
\hline
\end{tabular}

\section{Discussion}

Awareness of ORS among the study group was $74.4 \%$ and $25.6 \%$ were ignorant of the same. This lack of awareness among one fourth of the target mothers could be due to their illiteracy or lack of health campaigns. In a study by Bhan MK et $\mathrm{al}^{13} 86.2 \%$ of mothers were aware of ORS and $38.7 \%$ had already used it during diarrhea. So our results are similar to this study.

In present study first information of ORS was from health personnels (68.81\%) and $17.92 \%$ from mass media and the rest from relatives, peer group and neighbors (Table 1). In
(Table 3). In this study, only $26.88 \%$ mothers used exclusive ORS while $73.12 \%$ wanted ORS and medicines together (Table 4). UNICEF reports on the "state of world children" gave 25 percent utilization rate of ORS. Kumar $\mathrm{V}$ et al showed that $57.8 \%$ mothers were satisfied regarding ORS and remaining $42.2 \%$, had faith in medicines. Our study results agree with UNICEF, but not with the latter.

We found, only $12.54 \%$ and $22.33 \%$ mothers could prepare SSS and ORS correctly (Table 5,6 ). In one study it was observed that only few mothers could prepare ORS correctly. $^{19}$ Gopal Das et al ${ }^{20}$ also revealed similar results. Victoria CG et al ${ }^{15}$ revealed that correct knowledge of preparation of SSS by pinch method was only $16.6 \%$ and WHO-ORS only $41 \%$.In the present study only $24.1 \%$ mothers knew that freshly prepared ORS was fit for consumption within 24 hours only (Figure 1).

We found that feeds were withheld by 155 (27.8\%) mothers during diarrhoeal episode of their children, while $558(72.2 \%)$ continued feeding (Figure 2$)$. Green et al ${ }^{21}$ in their study observed restriction of food items by $75 \%$ mothers. Our study results do not agree with the author.

We conclude, that after extensive endeavors of the study, covering the entire vista of the problem of relationship of dehydration, diarrhoea and mortality, a consensus has developed to liberal use of ORS rather than undue and unwarranted antibiotics. 


\section{References}

1. UNICEF (December 2007).'The State of the Worlds Children 2008: Child Survival. p. 8.ISBN 978-92-8064191-2. http://www.unicef.org/publications/files/ The_State_of_the_Worlds_Children_2008.16.

2. WHO, UNICEF. "Oral Rehydration Salts: Production of the new ORS".http://libdoc.who.int/hq /2006/ WHO_FCH_CAH_06.1.pdf.

3. WHO: Programme for the Control of Diarrhoeal Diseases. "WHO/CDD/93.44: The selection of fluids and food for home therapy to prevent dehydration from diarrhoea: Guidelines for developing a national policy" . http://whqlibdoc.who.int/hq/1993/WHO_CDD_93.4 4. pdf.

4. Cesar G Victora, Jennifer Bryce, Olivier Fontaine, and Roeland Monasch. Reducing deaths from diarrhoea through oral rehydration therapy (pdf). Bulletin of the World Health Organization (WHO) 2000;78(10): 1246-55.00-0747. PMID 11100619. PMC 2560623.

5. UNICEF. Improved formula for oral rehydration salts to save children's lives".http://www.unicef.org/media/ media_31825.html.

6. "ORS Made at Home-rehydrate. org". http:// rehydrate.org/solutions/homemade.htm.

7. WHO(2005). The treatment of diarrhoea: A manual for physicians and other senior health workers. WHO/ FCH/CAH/05.1. ISBN 9241593180. http://whqlibdoc. who.int/publications/2005/9241593180.

8. WHO. "Pharmacopoeia Library: Oral Rehydration Salts". http://www.who.int/phint/en/p/docf/.

9. WHO. "The International Pharmacopoeia". http:// www.who.int/medicines/publications/pharmacopoeia/ QAS07_194rev1Zinc-sulf_FINAL.pdf (accessed 31 Dec. $20 \overline{1} 2)$.
10. WHO. "Zinc Sulfate for ORS for adults" (pdf). http://www.who.int/entity/medicines/publications/pha rmacopoeia/QAS07_194rev1Zinc-sulf_FINAL.pdf.

11. New formulation of Oral Rehydration Salts (ORS) with reduced os" UNICEF: 1molarity".

12. WHO. "Paediatric zinc sulfate oral solution" (pdf). http://www.who.int/entity/medicines/publications/pha rmacopoeia/QAS07_195rev1Zinc-sulf-oral-sol Final.pdf.

13. Bhan MK, Arora NK, et al. Major factors in diarrhoeal related mortality among rural children; Indian J Medical Research 2003;77:9-12.

14. Chaturvedi S, Sandhir M Bajpai. Importance of Mothers in home management of diarrhoea.

15. Victoria CG, Hutly SR. International difference in clinical pattern in diarrhoeal deaths, comparison from Brazil, Senegal, Bangladesh and India.Journal Diarrhoeal Dis Res 2005;13(2):106-12.

16. Sood AK, Umesh Kapil. Knowledge and practices among rural mothers in Haryana in childhood diarrhoea. Indian Journal Pediatr 2004;48:399-403.

17. Bannakappa DG, Nanda S. Brief report of WHOORT, Center of Vanivilas children Hospital, Banglore. Indian Journal of Pediatr 1990;57:21-24.

18. Kumar V, Kumar L, Divedi P. Morbidity Related feeding patterns in privilege urban and under privileged rural infants. Indian Pediatr 2005;15:743.

19. Martinez H, Sayucedo G. Mothers' Perception of childhood diarrhoea in rural Mexico. $J$ Diaorrheal Diseases Research 1991;9:235-43

20. Gopal Das T, Gujral S et al. Child diarrhoea, ORT and rural mother. Nutrition 1991;7:335-39.

21. Green E. Diarrhoea and Social Marketing of ORS in Bangladesh SOC. SCIMedicine 2006;3: 357-66. 